\title{
PEMBELAJARAN SAINS BERBASIS TRADISI SAINS ISLAM DI MADRASAH TSANAWIYAH (GERAK BENDA MENURUT IBNU BAJJAH)
}

\author{
Ade Putri ${ }^{1}$, Dalilah Nur Alip ${ }^{2}$
}

${ }^{1}$ Program Studi Pendidikan Fisika UIN SGD Bandung

\begin{abstract}
Banyak karya dari ilmuwan muslim yang belum dimanfaatkan sebagai bahan ajar IPA di Madrasah Tsanawiyah, umumnya bahan ajar yang diberikan di Madrasah Tsanawiyah sama dengan bahan ajar yang diberikan di SMP Penulisan ini bertujuan untuk mengungkap temuan ilmuwan muslim yang dapat digunakan sebagai bahan ajar IPA di Madrasah Tsanawiyah. Metode pembahasan yang digunakan dalam tulisan ini adalah sejarah sains berperspektif islam dan metode pembelajaran sains demonstratif. Data dikumpulkan melalui kepustakaan. Hasil penelitian mengungkapkan bahwa teori gerak dari Ibnu bajjah yang mempengaruhi Galileo Galilei dapat di ajarkan di Madrasah Tsanawiyah. Tujuannya untuk memperkaya wawasan murid tentang IPA berprespektif Islam.
\end{abstract}

Kata kunci: Teori gerak, Madrasah, Sains Berprespektif Islam

\section{PENDAHULUAN}

IPA (Ilmu Pengetahuan Alam) adalah ilmu pengetahuan yang mempelajari gejala-gejala melalui serangkaian proses yang dikenal dengan proses ilmiah yang dibangun atas dasar sikap ilmiah dan hasilnya terwujud sebagai produk ilmiah yang tersusun dari tiga komponen penting berupa konsep, prinsip, dan teori yang berlaku secara universal (Trianto, Model Pembelajaran Terpadu: Konsep, Strategi, dan Implementasinya dalam Kurikulum Tingkat Satuan Pendidikan 2013).

Pembelajaran IPA merupakan suatu pembelajaran yang menuntut sikap rasa ingin tahu dan keterbukaan terhadap ide-ide baru maupun kebiasaan berpikir analitis. Dalam pembelajaran IPA diharapkan guru dapat membekali peserta didik pengetahuan, pemahaman, dan sejumlah kemampuan untuk mengembangkan ilmu pengetahuan dan teknologi. Oleh karena itu, pembelajaran di sekolah harus menekankan pada pemahaman konsep IPA melalui keterampilan berpikir, keterampilan merespon suatu masalah secara kritis, dan keterampilan komunikasi.

UIN SGD Bandung

Email: adelp7980@gmail.com
(C)2017 Universitas Islam Negeri Walisongo 164

ISSN: 2088-7868, e-ISSN 2502-5708 
Salah satu permasalahan dalam proses pembelajaran IPA adalah masih rendahnya penguasaan konsep yang dimiliki siwa. Sehingga hasil belajar yang di dapatkan siswa kurang optimal. Hal ini disebabkan kurangnya keaktifan belajar siswa di dalam kelas. Selama ini pembelajaran yang diterapkan hanya menghafalkan fakta atau teori saja, dan memberi sedikit kesempatan siswa untuk terlibat aktif dalam proses pembelajaran (Trianto, Model Pembelajaran Terpadu: Konsep, Strategi, dan Implementasinya dalam Kurikulum Tingkat Satuan Pendidikan 2013).

Hal ini menyebabkan siswa kurang terdorong untuk mengembangkan kemampuan berpikir. Selain disebabkan karena kurangnya keaktifan siswa, penyebab lainnya adalah kurangnya pemanfaatan sumber belajar. Menurut Kamus Besar Bahasa Indonesia (KBBI) dijelaskan bahwa pemanfaatan terambil dari kata dasar manfaat yang artinya guna, faedah. Kemudian mendapatkan imbuhan pe-an yang berarti proses, cara, perbuatan pemanfaatan. Dengan demikian pemanfaatan dapat diartikan suatu cara atau proses dalam memanfaatkan suatu benda atau obyek. Namun dalam kegiatan belajar peserta didik ini ada kegiatan membelajarkan, misalnya yang dilakukan oleh penulis buku bahan ajar, atau pengembang paket belajar dan sebagainya (Yusufhudi 2004).

Dengan demikian, belajar yang sesungguhnya (the real learning) perlu adanya sumber belajar. Oleh karena itu sumber belajar adalah suatu sistem yang terdiri dari sekumpulan bahan atau situasi yang diciptakan dengan sengaja dan dibuat agar memungkinkan peserta didik belajar secara individual. proses belajar mengajar pada hakikatnya adalah proses komunikasi, yaitu proses penyampaian pesan dari sumber pesan melalui saluran/media tertentu ke penerima pesan. Pesan, sumber pesan, saluran/media dan penerima pesan adalah komponen-komponen proses komunikasi. Pesan yang akan dikomunikasikan adalah inti ajaran atau didikan yang ada dalam kurikulum. Sumber pesannya bias dari guru, siswa, orang lain ataupun penulis buku dan produser media. Salurannya adalah media pendidikan dan penerima pesannya adalah siswa atau juga guru.

Menurut Donald P. Ely (1978: 3) dalam (Warsita 2008) sumber belajar adalah data, orang, dan atau sesuatu yang memungkinkan peserta didik melakukan belajar. Sumber belajar meliputi semua sumber yang berkenaan dengan data, manusia, barangbarang yang memungkinkan dapat digunakan secara terpisah atau kombinasi, yang oleh peserta didik biasanya digunakan secara optimal untuk memberikan fasilitas dalam 
kegiatan belajar (Kenneth Silber, 1977: 8) dalam (Percival and Ellington 1988). Kemudian sumber belajar disebut sebagai satu set bahan atau situasi yang dengan sengaja diciptakan untuk menunjang peserta didik belajar mandiri

Berdasarkan uraian latar belakang di atas, maka dengan memanfaatkan sumbersumber belajar dalam pembelajaran tingkat SMP/Tsanawiyah diperkirakan dapat dijadikan alternatif dalam pembelajaran IPA-fisika agar siswa dapat memperoleh pengetahuan yang lebih dalam pembelajaran IPA sehingga dapat berpengaruh terhadap hasil belajar siswa.

Artikel ini bertujuan untuk memperkaya wawasan murid tentang IPA berprespektif Islam.

\section{METODE PENELITIAN}

Artikel ini dibuat dengan menggunakan metode penelitian kualitatif dengan pendekatan filsafat sejarah sains islam. Adapun metode yang digunakan untuk mengumpulkan data adalah metode studi pustaka, yaitu dengan mencari informasi baik dari buku, jurnal dan artikel.

\section{HASIL DAN PEMBAHASAN}

Ibnu Bajjah atau nama lengkapnya Abu Bakar Muhammad bin Yahya bin ashshayigh at-Tujibi bin Bajjah adalah seorang astronom, filusuf, musisi, dokter, fisikawan, psikolog, botanis, sastrawan, dan ilmuwan muslim Andalusia yang dikenal di Barat dengan nama latinnya Avempace. Ia lahir di Zaragoza, tempat yang kini bernama Spanyol, dan meninggal di Fez pada 1138 M. Pemikirannya memiliki pengaruh yang jelas pada Ibnu Rushdi dan Albertus Magnus. Ia memiliki pengetahuan yang luas pada kedokteran, Matematika, dan Astronomi (Wikipedia n.d.).

Dalam bidang fisika, Ibnu Bajjah mengungkapkan hukum gerak. Prinsip-prinsip yang dikemukakannya itu menjadi dasar bagi pengembangan ilmu mekanik modern. Pemikirannya dalam bidang fisika banyak memengaruhi fisikawan Barat abad pertengahan, seperti Galileo Galilei. Tak heran, jika hukum kecepatan yang dikemukakannya sangat mirip dengan yang dipaparkan Galilei. Ibnu bajjah mendefinisikan tentang kecepatan pada saat benda bergerak, yang mana definisi 
tersebut sama dengan definisi dari Galileo Galilei. Ia menyatakan bahwa Kecepatan = Gaya gerak - Resistansi Materi (M. A. Ernest 1951).

Dimana gaya gerak diukur dengan gravitasi spesifik benda yang bergerak dan resistansi material adalah media penahan yang daya resistifnya diukur dengan gravitasi spesifiknya. Ibn Bajjah adalah orang pertama yang menyatakan bahwa selalu ada gaya reaksi untuk setiap gaya yang diberikan, pendahulu gagasan Gottfried Leibniz tentang gaya yang mendasari hukum gerak ketiga Newton atau hukum aksi-reaksi (Shlomo 1964). Namun, sejarah dari prinsip aksi dan reaksi dapat ditelusuri melalui pemikiran dari Aristoteles.

Avempace menganggap prinsip bahwa segala sesuatu tergerak oleh sesuatu yang lain, dan mengatakan:

"Jelaslah bahwa selebihnya dari keseluruhan karena sisa salah satu bagiannya berlangsung sejauh yang bergerak selain penggeraknya, dan ketika pengaruh yang terakhir berakhir, ia akan berhenti. Pengaruhnya berakhir karena penggerak berhenti bertindak sendiri atau karena sesuatu yang lain memberikan perlawanan terhadapnya. Kapan pun penggerak berhenti bertindak sendiri, ini terjadi baik akibat kehancurannya, atau karena kelelahan (kalâl) dari kekuatan penggerak, atau karena penyebabnya hilang, karena pergerakannya telah mencapai Akhir ke arah mana ia bergerak" (Lettinck 1994).

Gerakan di sini disebut dengan gerak "Paksa". Ibn Bâjja membuat sketsa teori dinamika berdasarkan gagasan "kekuatan" yang berbeda dari gagasan dinamika Aristoteles tentang dinamika: Dinamika adalah kekuatan mekanis yang dapat bergabung dengan kekuatan lain atau melawannya dengan menawarkan perlawanan. Ada jumlah minimum daya bergerak untuk setiap gerakan benda. Misalnya, untuk menggerakkan sebuah kapal dibutuhkan daya minimum, jika tidak "sebutir pasir bisa menggerakkan kapal" (Ibn Bâjja 1973, 112: 27) dalam (Montada 2007).

Avempace mengemukakan teori berkaitan dengan gerak dalam ruang hampa. Analisa Avempace mengenai gerak "alami" seperti batu jatuh melalui udara dan air. benda-benda yang bergerak ini membutuhkan daya untuk bergerak tidak hanya pada cara bagaimana gerakan benda tersebut, tetapi juga melalui media melalui mana benda tersebut akan bergerak. partikel debu tetap melayang di udara karena, meskipun memiliki daya yang cukup untuk turun, daya tersebut tidak cukup untuk melewati udara. 
Teori tentang gerak dalam ruang hampa ini telah dikemukakan jauh sebelum Ibnu bajjah mengemukakannya, Aristoteles telah dahulu mengemukakan tentang teori tentang gerak ini. Aristoteles menolak kemungkinan gerak dalam ruang hampa karena medium sangat penting untuk pergerakan alami pada kecepatan yang terbatas. Namun ada beberapa kritik mengenai teori Aristoteles ini, seperti yang dikemukakan oleh Philoponus. Philoponus menegaskan, bahwa keberadaan kekosongan itu mungkin dan kemudian dia berbicara tentang gerak dalam kekosongan juga. Menurut pendapat dari Philoponus, entitas dasar dan utama yang menentukan gerakan adalah daya gerak. Jika tubuh bergerak dalam kehampaan, daya gerak membuatnya berjalan di tempat tertentu Dalam waktu tertentu. Jika sebaliknya tubuh bergerak dalam media tertentu, ia bertemu dengan Resistensi tertentu yang sebanding dengan kepadatan medium dan oleh karena itu seseorang harus menambahkan waktu tambahan ke waktu utama (yaitu itu diambil untuk bergerak dalam kekosongan) (Boccaletti 2016).

Selain itu, kritikan mengenai teori Aristoteles juga dikemukakan oleh Avempace. Menurut pendapat Avempace, mediumnya tidak penting untuk gerak alami dengan kecepatan yang terbatas karena kecepatan geraknya ditentukan oleh perbedaan dan tidak dengan rasio, antara kepadatan tubuh dan media. Oleh karena itu, V = F - R, sehingga bila $\mathrm{R}=0, \mathrm{~V}=\mathrm{F}$ ( $\mathrm{F}$ adalah Kekuatan motif yang diukur dengan gaya berat tubuh yang bergerak, $\mathrm{R}$ daya tahan medium diukur dengan gravitasi spesifiknya, $\mathrm{V}$ kecepatan). Perlu dicatat bahwa Avempace tidak mengatakan bagaimana gerak tersebut, dalam besarannya karakterisasi itu (A. M. Ernest 1951).

Ibnu Bajjah melihat gerakan sebagai kinematis di alam, tapi pembangunan analisis kinematis ini setara dengan daya gerak atau gaya. Dengan kata lain, penjelasan tersebut masih terkandung pandangan bahwa gerak yang tidak berdiferensiasi terdiri dari Dinamis dan Kinematis. Avempace di sisi lain percaya bahwa gaya bekerja pada benda-benda yang tahan material. Namun, ia menganggap bahwa gerak itu tanpa gaya tidak mungkin. Selanjutnya, Santo Thomas Aquinas dan William dari Ockham mendukung kinematika pandangan gerak Ockham khususnya melihat adanya Perbedaan mendasar antara kondisi 'Sedang bergerak' dan kondisi 'sedang Pindah', dalam arti dipengaruhi oleh sebuah gaya (Espinoza 2005).

Ibnu Bajjah pun sangat memengaruhi pemikiran Thomas Aquinas mengenai analisis gerakan. Inilah salah satu bukti betapa peradaban barat banyak terpengaruh 
dengan sains yang dikembangkan ilmuwan Muslim.Sebagaimana dalam bukunya Systeme $d u$ Monde, sejarawan perintis ilmu pengetahuan abad pertengahan, Pierre Duhem, menyatakan:

"Untuk pertama kalinya kita melihat akal manusia membedakan dua unsur dalam tubuh yang berat: gaya gerak, yang dalam pengertian modern dinyatakan sebagai berat, dan gerak benda, kuantum korpus, atau yang saat ini kita sebut massa. Untuk pertama kalinya kita melihat gagasan tentang massa diperkenalkan dalam mekanika, dan diperkenalkan setara dengan apa yang tersisa dalam tubuh ketika seseorang telah menekan semua bentuk agar hanya meninggalkan masalah utama yang diukur oleh dimensi yang ditentukan. Analisis dari Thomas Aquinis ini melengkapi teori dari Ibn Bajjah, analisis dari Thomas Aquinas mempertimbangkan 3 keadaan ketika benda jatuh: berat, massa, dan hambatan medium, tentang bagaimana fisika akan menjawab kejadian yang terjadi selama era modern. Massa ini, benda yang diukur ini, menolak pergerakan yang mencoba mengangkutnya dari satu tempat ke tempat lain, kata Thomas Aquinas ". Dinamika adalah Cabang dari ilmu mekanika yang meninjau gerak partikel dengan meninjau penyebab geraknya. Dalam bagian ini kita akan membahas konsep-konsep yang menghubungkan kondisi gerak benda dengan keadaan-keadaan luar yang menyebabkan perubahan keadaan gerak benda (Satriawan n.d.).

Bila sebuah benda berada dalam keadaan diam, untuk menggerakkannya dibutuhkan pengaruh luar. Misalnya untuk menggerakkan sebuah balok yang diam di atas lantai, kita dapat mendorongnya. Dorongan kita ini adalah pengaruh luar terhadap balok tadi yang menyebabkan benda tersebut bergerak.

Kesimpulan ini, yang pertama kali disimpulkan oleh Galileo Galilei, dikenal sebagai prinsip inersia atau kelembaman. Benda-benda cenderung untuk mempertahankan kondisi geraknya, bila dia diam, akan tetap diam dan bila bergerak, akan tetap bergerak dengan kecepatan konstan, selama tidak ada pengaruh luar yang mengubah kondisi geraknya.

Galileo menyatakan bahwa semua benda, berat atau ringan jatuh dengan percepatan yang sama, paling tidak jika tidak ada udara. Jika kita memegang selembar kertas secara horizontal pada suatu tangan dan sebuah benda lain yang lebih berat misalnya saja bola. Kemudian kamu melepaskan kedua benda tersebut, benda yang lebih berat akan lebih dahulu mencapai tanah. Tetapi jika kita mengulangi percobaan 
dengan mengubah bentuk kertas menjadi gumpalan kecil, kita akan melihat bahwa kedua bentuk benda tersebut mencapai lantai pada saat yang hampir sama. Galileo yakin bahwa udara berperan sebagai hambatan untuk benda-benda yang sangat ringan yang memiliki permukaan yang luas. Tetapi pada banyak keadaan biasa, hambatan udara ini bisa diabaikan. Pada suatu ruang di mana udara telah dihisap, maka benda ringan sepertii bulu atau selelmbar kertas yang dipegang secara horizontalpun akan jatuh dengan percepatan yang sama seperti benda lain.

Sumbangan galileo yang spesifik terhadap pemahaman kita tentang gerak benda jatuh dapat dirangkum sebagai:

"Pada suatu lokasi tertentu di Bumi dan dengan tidak adanya hambatan udara, semua benda jatuh dengan percepatan konstan yang sama."

Kita menyebut percepatan ini sebagai percepatan yang disebabkan oleh gravitasi pada bumi, dan memberikan symbol $g$. yang besarnya sekitar $g=9.8 \mathrm{~m} / \mathrm{s}^{2}$. (Giancoli 2001)

Hal ini tentu memiliki persamaan dengan analisis Ibnu bajjah mengenai gerak benda, di mana Ibnu Bajjah mengemukakan bahwa kecepatan pada saat benda bergerak adalah sebanding dengan kecepatan akhir dan hambatan dari mediumnya. $\mathrm{V}=\mathrm{F}-\mathrm{R}$, di mana $\mathrm{F}$ adalah gaya saat benda bergerak dan $\mathrm{R}$ adalah resistansi atau hambatan yang dalam hal ini adalah udara. Artinya pada saat hambatan udara diabaikan maka benda akan jatuh pada percepatan yang sama, karena udara merupakan suatu hambatan yang dapat memperlambat pergerakan benda.

Salah satu contoh gerak dengan percepatan konstan adalah gerak jatuh bebas. Benda yang dilepas dari ketinggian $\mathrm{h}$ akan mendapat percepatan dari gravitasi bumi yang besarnya dapat dianggap konstan menuju bumi. Kecepatan awal benda adalah nol (Palupi, Suharyanto and Karyono 2009).

Gerak jatuh bebas didefinisikan sebagai gerak suatu benda yang dijatuhkan dari ketinggian tertentu di atas tanah tanpa kecepatan awal dan dalam geraknya hanya dipengaruhi oleh gaya gravitasi. Terminologi jatuh bebas digunakan untuk benda yang jatuh tanpa memilik kecepatan awal akibat suatu gaya $\left(V_{0}=0\right)$. Untuk menganalisis gerakan ini, maka dapat dilihat bahwa gerakan hanya dipengaruhi oleh gaya gravitasi bumi. Bukan massa benda. Benda yang jatuh, semakin dekat ke permukaan bumi, kecepatanya akan semakin bertambah. Karena benda mengalami percepatan sebesar percepatan gravitasi bumi. Persamaan gerak yang digunakan untuk menganalisis 
gerakan ini adalah persamaan gerak untuk gerak lurus berubah beraturan (Anonim 2012).

\section{SIMPULAN DAN SARAN}

Berdasarkan hasil dan pembahasan didapatkan persamaan teori tentang gerak benda Ibnu Bajjah dengan Galileo Galilei, hal ini menandakan bahwa sebelum Galileo Galilei mengemukakan pendapatnya tentang gerak benda Ilmuwan muslim telah lebih dahulu menemukannya, adapun dalam pembahasan yang disajikan ini bertujuan agar peserta didik dapat memperluas wawasan mereka tentang sains dan memotivasi peserta didik agar memiliki sikap menghargai bahwa ilmuwan muslim sangat mempengaruhi perkembangan sains khususnya pada bidang fisika. Dan mengembangkan potensi peserta didik dalam menjadi ilmuwan yang kaya akan pengetahuan dan berakhlakul karimah. Diharapkan penelitian berlanjut tidak terbatas pada pandangan satu ilmuwan muslim.

\section{DAFTAR RUJUKAN}

"Abel B Franco." Journal of the History Ideas 64, no. 4 (n.d.): 543.

Anonim. Juni 2012.

https://marojahantampubolon.files.wordpress.com/2012/06/pagefrom_bahankuliah-fisika-untuk-universitas.pdf (accessed Mei Senin, 2017).

Anonim. "Concept Reaction Ibnu Bajjah." In Islam, 376. Wikipedian, n.d.

B, Franco Abel. "Avempace, Projectile Motion, and Impetus Theory." Journal of the History of Ideas, 2003.

Boccaletti, D. The Theories of Motion in the Middle Ages. Springer International Publishing Switzerland, 2016.

Ernest, A Moody. Galileo and Avempace: The dynamics of the Leaning. Vol. 12. Journal of History of Ideas, 1951.

Ernest, Moody A. "Galileo and Avempace: The Dynamics of the Leaning Tower Experiment (II)." Journal of the History of Ideas 12, no. 3 (1951): 375-422.

Espinoza, Fernando. "An analysis of the historical develpoment of ideas about motion and its implications for teaching." Journal Physics, 2005: 141.

Fred, Percival, and Henry Ellington. In Teknologi Pendidikan. Jakarta: Erlangga, 1988. 
Giancoli, Douglas C. In Fisika Edisi Kelima Jilid 1, 38-39. Jakarta: Erlangga, 2001.

Hasse, D N. "Das Lehrstück von den vier Intellekten in der Scholastik: von den arabischen Quellen bis zu Albertus Magnus", Recherches de Théologie et Philosophie médiévales." 66 (1999): 21-77.

Lettinck, Paul. In Aristotle's physics and its reception in the Araic World with an edition of the unpublished Parts of ibnu Bajja's , 532-533. Leiden: Brill, 1994.

Montada, Puig Josep. September Friday, 2007. https://plato.stanford.edu/entries/ibnbajja/ (accessed May Monday, 2017).

Moody, Ernest A. "Galileo and Avempace: The Dynamics of the Learning Tower Experiments (II)." Journal of the History of Ideas 12, no. 3 (June 1951): 375422.

Palupi, Dwi Satya, Suharyanto, and Karyono. In Fisika untuk SMA dan MA Kelas IX Jilid 2, 27. Yogyakarta: CV Sahabat, 2009.

Percival, Fred, and Henry Ellington. In Teknologi Pendidikan, 124. Jakarta: Erlangga, 1988.

Prabaningrum, Dwi Pujianingtyas. TOKOH FILSAFAT BARAT PADA ABAD PERTENGAHAN

(Thomas

Aquinas).

https://afidburhanuddin.files.wordpress.com/2012/11/thomas-aquinas_ed.pdf, 2012.

Putri, Fitria Eka. "Filsafat Thomas Aquinas." 2012: 1.

Satriawan, Mirza. n.d. http://mirza.staff.ugm.ac.id/fisdas/note2.pdf (accessed May Monday, 2017).

Shlomo, Pines. "La dynamique d'Ibn Bajja" in Melanges Alexandre Koyre. Paris, 1964.

Trianto. In Model Pembelajaran Terpadu: Konsep, Strategi, dan Implementasinya dalam Kurikulum Tingkat Satuan Pendidikan, 145. Jakarta: Bumi Aksara, 2013.

Trianto. In Model Pembelajaran Terpadu: Konsep, Strategi, dan Implementasinya dalam Kurikulum Tingkat Satuan Pendidikan. Jakarta: Bumi Aksara, 2013.

Trianto. In Model Pembelajaran Terpadu: Konsep, Strategi, da Implementasinya dalam Kurikulum Tingkat Satuan Pendidikan (KTSP), 141. Jakarta: Bumi Aksara, 2013.

Trianto. In Model Pembelajaran Terpadu: Konsep, Strategi, dan Implementasinya dalam Kurikulum Tingkat Satuan Pendidikan, 141. Jakarta: Bumi Aksara, 2013. 
Warsita. In Teknologi Pembelajaran Landasan dan Aplikasinya. Jakarta: Rineka Cipta, 2008.

Wikipedia. n.d.

Yusufhudi, Miarso. In Menyemai Benih Teknologi Pendidikan, 553-554. Jakarta: Prenada Media, 2004. 